injury are probably due to increased intracranial pressure, ${ }^{3}$ but there was no question of this in our patient either symptomatically or on computed tomography.

The most logical explanation for the haematoma in our patient was shearing injury to the blood vessels supplying the lower midbrain and upper pons with no damage to brain stem tissue, which might explain why he remained alert and conscious.

' Crompton MR. Brainstem lesions due to closed head injury. Lancet $1971 ; \mathrm{i}: 669-73$.

${ }^{2}$ Mitchell DE, Adams JH. Primary focal impact damage to the brainstem in blunt head injuries: does it exist ? Lancet 1973;ii:215-8.

${ }^{3}$ Adams JH, Mitchell DE, Graham DI, Doyle D. Diffuse brain stem damage of immediate impact type. Its relationship to "primary brain stem damage" in head injury. Brain 1977;100:489-502.

(Accepted 25 October 1983)

Department of Neurology, Faculty of Medicine, Kuwait University, and Ibn Sina Hospital, Kuwait

R A SHAKIR, MB, MRCP, consultant neurologist

R A KHAN, MD, registrar

Correspondence to: Dr R A Shakir, Faculty of Medicine, PO Box 24923, Safat, Kuwait.

\section{Severe bronchoconstriction after inhalation of budesonide}

Budesonide is a synthetic non-halogenated glucocorticoid that has recently been introduced as an aerosol for the treatment of asthma. ${ }^{1}$ We report a case of severe bronchoconstriction after inhalation of budesonide aerosol.

\section{Case report}

A 63 year old businessman with moderately severe intrinsic asthma received regular maintenance treatment with a beclomethasone pressurised aerosol (Becotide) and a salbutamol aerosol (Ventolin), with occasional short courses of oral steroids. He developed symptomatic oral candidiasis, and beclomethasone was stopped. He was prescribed a budesonide pressurised spacer inhaler (Pulmicort). The following morning he felt wheezy but went to work after using his bronchodilator, collecting his new Pulmicort inhaler on the way. On arrival at his office he inhaled one puff of budesonide $(200 \mu \mathrm{g})$ for the first time and almost immediately developed rapidly increasing shortness of breath and wheeze. Within a few minutes he was so dyspnoeic that he could not call out or use his telephone to summon help. He thought he was dying. He was found and rushed to hospital. On arrival he was distressed and very wheezy and was given intravenous aminophylline. His forced expiratory volume in one second was subsequently measured at $700 \mathrm{ml}$. His condition improved, and he was given a reducing course of oral steroids. He was then started on a regular betamethasone aerosol (Bextasol) and bronchodilators. Measurements at home of his peak flow rate showed that his condition returned to a stable state.

Two months later he attended the lung function laboratory and was challenged with two puffs from the same Pulmicort inhaler that he had used before. Within 10 minutes he was very wheezy and dyspnoeic and his forced expiratory volume in one second had fallen by $41 \%$ (from a mean baseline of 1.451 ), his forced vital capacity by $34 \%$ (from 3.251 ), and his peak flow rate by $29 \%$ (from $233 \mathrm{l} / \mathrm{min}$ ). Subsequent inhalation of nebulised salbutamol caused a rapid improvement in symptoms and lung function. On separate occasions he was then challenged in a single blind manner with two puffs from a different Pulmicort aerosol and two puffs and later four puffs from an Astra placebo aerosol canister. (Two puffs of the placebo contained the same amount and type of fluorocarbon propellants as one puff of Pulmicort.) Appreciable bronchoconstriction again developed with Pulmicort (table). Lesser bronchoconstriction was seen with the placebo, especially after four puffs.

Percentage fall in forced expiratory volume ( $F E V_{1}$ ), forced vital capacity (FVC), and peak flow rate (PFR) after challenge with two different budesonide aerosols and a placebo

\begin{tabular}{lccc}
\hline Inhaled challenge & $\%$ fall in FEV & $\%$ fall in FVC & $\%$ fall in PFR \\
\hline 2 puffs budesonide: & & & \\
First challenge & 41 & 34 & 29 \\
Second challenge & 35 & 28 & 19 \\
2 puffs placebo & 20 & 10 & 11 \\
4 puffs placebo & 21 & 16 & 17 \\
\hline
\end{tabular}

\section{Comment}

Pressurised aerosols based on fluorocarbons are now widely used in the management of asthma. Bryant and Pepys investigated three patients who developed wheezing after inhalation of beclomethasone diproprionate (Becotide) and found similar bronchoconstriction after inhalation of a placebo aerosol containing only the propellant vehicle (fluorocarbons 11 and 12). ${ }^{2}$ These patients did not react, however, to bronchial challenge with gaseous fluorocarbons obtained by heating the liquid propellants to boiling point, suggesting that other factors apart from fluorocarbons were important. Aerosols also contain a detergent (sorbitan trioleate in Pulmicort, oleic acid in Becotide), a rubber metering valve, and possibly also contaminants from the aluminium can. Sensitivity or non-specific bronchial reactivity to these components may be possible. Indeed, we have repeatedly noted a pungent rubbery smell after the delivery of budesonide. In a single blind study we found that eight of 10 normal subjects coughed spontaneously after inhaling one metered dose of budesonide but that only two of the same subjects coughed after beclomethasone.

Our patient developed appreciable bronchoconstriction to both budesonide and its propellants (trichlorofluoromethane, dichlorodifluoromethane, and dichlorotetrafluoroethane). This may be an idiosyncratic reaction, but it will be important to know whether further cases of bronchoconstriction develop after inhalation of this new steroid preparation.

We reported our findings to the Committee on Safety of Medicines and to Astra Pharmaceuticals. No similar cases have been reported to date.

We thank Dr A Higgins and Mr A Gay of Astra Pharmaceuticals for their help in preparing this report.

${ }^{1}$ Ellul-Micallef R, Hansson E, Johansson SA. Budesonide: a new corticosteroid in bronchial asthma. Eur $\mathcal{f}$ Respir Dis 1980;61:167-73.

${ }^{2}$ Bryant DH, Pepys J. Bronchial reactions to aerosol inhalant vehicle. $\mathrm{Br}$ Med f 1976; i:1319-20.

(Accepted 2 November 1983)

City Hospital, Nottingham NG5 1PB

D V MCGIVERN, BM, MRCP, medical registrar

J T MACFARLANE, DM, MRCP, consultant physician

Correspondence to: Dr D V McGivern.

\section{Legs that swell and ache: volume changes during the day in healthy young adults}

Complaints of aching, heavy, or swollen legs are common among people who stand for long periods, and particularly among pregnant women, the obese, and those with varicose veins. We carried out a study to establish whether such complaints in fit young adults were associated with leg swelling and whether such swelling was influenced by sex, build, or menstrual cycle.

\section{Subjects, methods, and results}

We studied 20 junior doctors (10 m.en, 10 women) during an "ontake" day. None was pregnant or had varicose veins. At 0800 we measured each subject's height and weight. Leg volume was measured by lowering the left leg into a rigid Perspex container filled with water to the level of a side spout at a height of $46 \mathrm{~cm}$ and measuring the volume of water displaced when the subject was standing with weight equally distributed between both feet. Leg volume was measured again at 1300 and 2200 . On each occasion subjects reported whether they had been busy over the preceding few hours, and at the end of the day they recorded on a linear analogue scale any aching in the legs.

All subjects showed a significant increase in leg volume during the day. The mean (SE) increase was $2.79(0.4) \%$ by $1300(t=6.86, \mathrm{p}<0.001)$ and $3.74(0.64) \%$ by $2200(t=8.42, \mathrm{p}<0.001)$. These increases were not influenced by sex, height, weight, obesity index (weight/height ${ }^{2}$ ), or level of activity. Women who did not wear tights $(n=3)$ had a greater increase in leg volume than those who did (mean $3.19(0.72) \%$ v $2.61(0.54) \%$ ), but the difference was not significant. Subjects who complained of aching legs (seven men, seven women) had significantly more leg swelling by 2200 than those who did not (mean $4.38(0.47) \%$ v $2.25(0.75) \% ; t=2.43, \mathrm{p}<0.05)$. 
We also studied 10 fit women volunteers aged 21-36 two to four days before and six to eight days after the onset of menstruation. Height, weight, and leg volume were measured at the beginning and end of a working day, and leg symptoms at the end of the day were recorded.

Almost every subject had lost height and weight after menstruation, but leg volume increased in some and decreased in others and the changes were not significant. The amount of leg swelling and severity of symptoms at the end of the day were no different before and after menstruation. There were no differences in basal leg volume and leg swelling between those taking oral contraceptives $(n=6)$ and those not.

\section{Comment}

We found a significant increase in leg volume during the day in fit young adults, and almost three quarters of this swelling occurred in the morning. The legs that ached were those that swelled most. The increase in leg volume may be due to increased interstitial fluid and venous distension, and accumulation of metabolites or passive stretching of skin, fascia, and veins may cause aching.

Body weight increases before menstruation due to salt and water retention induced by oestrogen and progesterone. ${ }^{12}$ An increase in total body water might result in greater leg volume. It is therefore surprising that in our study neither basal leg volume nor leg swelling were greater before menstruation. This finding may be related to the fact that none of our subjects experienced any premenstrual symptoms.

1 Okey R, Stewart D. Diet and blood cholesterol in normal women. $\mathcal{F}$ Biol Chem 1933;99:717-27.

2 Thorn GW, Nelson KR, Thorn DW. Study of mechanism of edema associated with menstruation. Endocrinology 1938;22:155-63.

(Accepted 25 October 1983)

Nuffield Department of Surgery, John Radcliffe Hospital, Oxford L HANDS, MB, FRCS, surgical registrar

J COLLIN, MD, FRCS, reader in surgery and consultant surgeon

Correspondence to: Miss L Hands.

\section{Lung abscess and reactive arthritis: rare complications of leptospirosis}

Leptospirosis is rare, about 60 cases being diagnosed each year in the United Kingdom, with a mortality of $5 \%{ }^{1}$ We have found only one previous report of reactive arthritis and none of lung abscess complicating leptospirosis. We report on a patient with both complications.

\section{Case report}

A 52 year old civil engineer presented with a six day history of abdominal pain, headache, nausea, and vomiting. Fourteen days previously he had cut his hand in a drain. On admission to hospital he was shocked with an unrecordable blood pressure, jaundiced, and tachypnoeic. Haemoglobin concentration was $14.3 \mathrm{~g} / \mathrm{dl}$; white cell count $1.6 \times 10^{9} / 1$ (73\% neutrophils); platelet count $55 \times 10^{9} / 1$; prothrombin ratio 1.6 ; and concentrations of fibrinogen degradation products $10-40 \mathrm{mg} / 1$, urea $12 \mathrm{mmol} / 1(72 \cdot 1 \mathrm{mg} / 100 \mathrm{ml})$ sodium $130 \mathrm{mmol}(\mathrm{mEq}) / 1$, potassium $3.4 \mathrm{mmol}(\mathrm{mEq}) / 1$, and bilirubin 170 $\mu \mathrm{mol} / 1(10 \mathrm{mg} / 100 \mathrm{ml})$; liver enzyme activity was slightly raised. An electrocardiogram showed no abnormality other than sinus tachycardia. An $x$ ray film showed bilateral basal shadowing. A leptospiral complement fixation test showed a rise in titre from $1 / 10$ on the third day in hospital to $1 / 2560$ on the 15th day. Agglutination tests showed cross reaction with several serotypes. Multiple blood cultures gave negative results, and there was no serological evidence of other pathogens.

Initial treatment included intravenous methylprednisolone, fluid replacement, azlocillin, gentamicin, and metronidazole. He had anuria with evidence of acute tubular necrosis, and peritoneal dialysis was started. After 24 hours a chest $x$ ray film showed extensive pneumonitis (figure (top)), and because of increasing respiratory distress mechanical ventilation with positive end inspiratory pressure was started. Profuse amounts of heavily bloodstained secretions were aspirated from the endotracheal tube throughout the following 15 days. After 28 days the pneumonitis had partially resolved, which permitted extubation, although cavitation in the left upper lobe rapidly developed into a large abscess (figure (bottom)). On fibreoptic bronchoscopy the left upper lobe bronchus was patent, although the mucosa throughout appeared floridly haemorrhagic. Bronchial washings yielded Pseudomonas aeruginosa; anaerobic culture was negative and dark ground microscopy showed no leptospira. After
21 days' treatment with chloramphenicol and metronidazole his symptoms had resolved completely, and he was discharged from hospital with normal hepatic and renal function.

After three weeks he presented again with severe arthritis of acute onset affecting the spine, shoulders, and knees, and morning stiffness lasting three hours. There was generalised muscle wasting; limitation of movement of the spine, shoulders, and knees; and prominent bilateral heel tenderness. Erythrocyte sedimentation rate was $47 \mathrm{~mm}$ in the first hour. Tests for rheumatoid factor and antinuclear factor were negative. $X$ ray films of the hands, knees, heels, and lumbar spine were normal. He was negative for HLA B27. His symptoms did not improve after treatment with a series of nonsteroidal anti-inflammatory drugs, but partially responded to high doses of prednisolone.
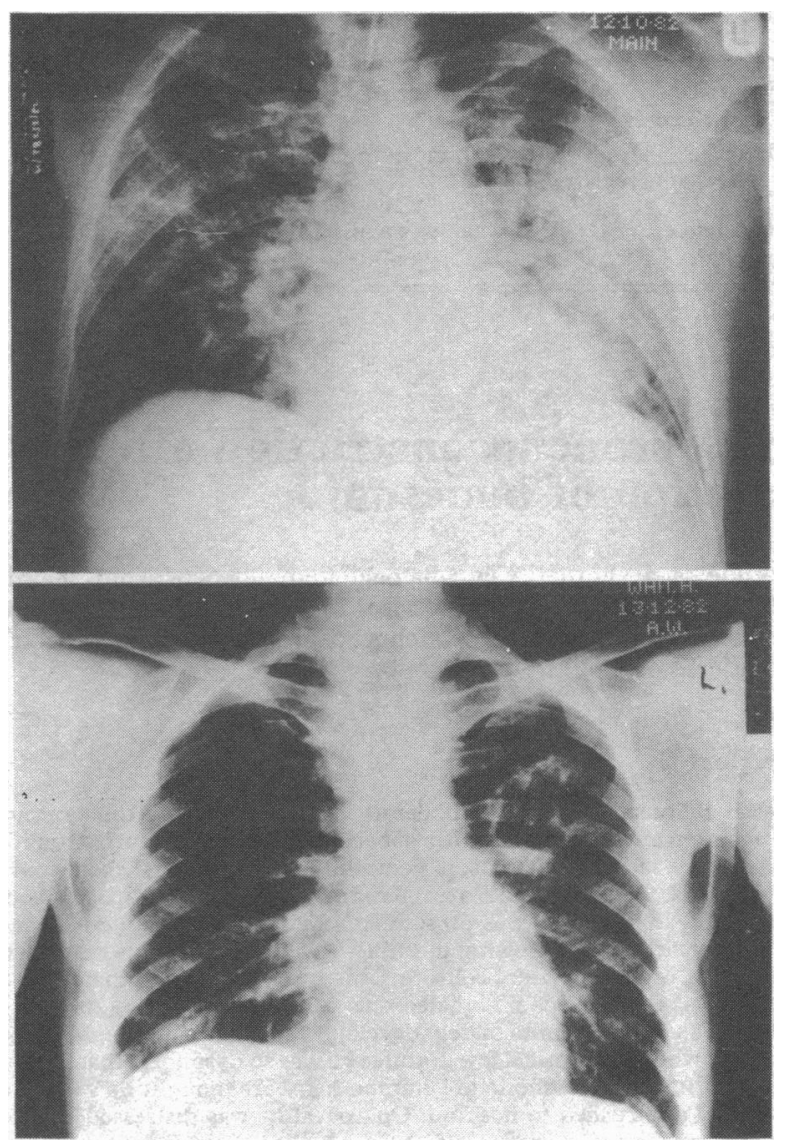

Chest $x$ ray film showing (top) extensive pulmonitis before ventilation and (bottom) cavitation and large abscess in left upper lobe.

\section{Comment}

Lung disorders have been reported in $11 \%$ of patients with leptospirosis, often as incidental findings ${ }^{2}$ but occasionally, as the major manifestation of the disease, presenting as haemoptysis ${ }^{3}$ or adult respiratory distress. ${ }^{4}$ Pathologically the pulmonary lesions are pneumonitis with interstitial oedema and haemorrhage, and the likely mechanism is a direct toxic effect on the vascular endothelium, exacerbated in this case by prolonged caogulation times and thrombocytopenia.

Although Heath et al frequently found arthralgia in the prodromal phase of leptospirosis, ${ }^{2}$ we have found only one report of acute arthritis after the initial infection. ${ }^{5}$ Uveitis and prostatitis have been described after leptospirosis, ${ }^{2}$ which provides further evidence of "reactive" responses to the acute infection. Hypertrophic osteoarthropathy but not reactive arthritis may be associated with lung abscess, and our patient's lung disease alone is unlikely to have accounted for his arthritis. We suggest that leptospirosis should be added to the increasing number of infectious diseases that lead to reactive arthritis.

${ }^{1}$ Coghlan JD. Leptospirosis in man, British Isles, 1978. Br Med $\mathcal{F} 1979$;ii : 872-3.

${ }^{2}$ Heath CW, Alexander AD, Hatton MM. Leptospirosis in the United 